\title{
Anatomical Study of the Extreme Lateral Transpsoas Lumbar Interbody Fusion with Application to Minimizing Injury to the Kidney
}

Joe Iwanaga ${ }^{1}$, Emre Yilmaz ${ }^{2}$, Tamir Tawfik ${ }^{3}$, Amir Abdul-Jabbar ${ }^{4}$, Marc Vetter ${ }^{5}$, Marc Moisi ${ }^{6}$, Koichi Watanabe ${ }^{7}$, Koh-ichi Yamaki ${ }^{8}$, R. Shane Tubbs ${ }^{6}$, Rod J. Oskouian ${ }^{9}$

1. Medical Education and Simulation, Seattle Science Foundation, Seattle, USA 2. Surgery, Swedish Neuroscience Institute, Seattle, USA 3. Swedish Medical Center, Swedish Neuroscience Institute 4. Orthopaedics, Swedish Neuroscience Institute, Seattle, USA 5. Seattle Science Foundation, Seattle, USA 6. Neurosurgery, Seattle Science Foundation, Seattle, USA 7. Department of Anatomy, Kurume University School of Medicine 8. Department of Anatomy, Kurume University School of Medicine, Kurume, JPN 9. Neurosurgery, Swedish Neuroscience Institute, Seattle, USA

$\square$ Corresponding author: Marc Vetter, vettermj@plu.edu Disclosures can be found in Additional Information at the end of the article
Received 01/23/2018 Review began $01 / 25 / 2018$ Review ended 01/25/2018 Published 01/29/2018

\section{(๑) Copyright 2018}

Iwanaga et al. This is an open access article distributed under the terms of the Creative Commons Attribution License CC-BY 3.0., which permits unrestricted use, distribution, and reproduction in any medium, provided the original author and source are credited.

\section{Abstract}

\section{Objective}

Since the extreme lateral lumbar interbody fusion procedure was first reported by Ozgur in 2006, a large number of clinical studies have been published. Anatomical studies which explore methods to avoid visceral structures, such as the kidney, with this approach have not been examined in detail. We dissected the retroperitoneal space to analyze how the extreme lateral transpsoas approach to the lumbar spine could damage the kidney and related structures.

\section{Methods}

Eight sides from four fresh Caucasian cadavers were used for this study. The latissimus dorsi muscle and the thoracolumbar fascia were dissected to open the retroperitoneum. The fat tissue was removed. Steel wires were then put into the intervertebral disc spaces. Finally, the closest distance between kidney and wires on each interdiscal space was measured.

\section{Results}

The closest distance from the wire in the interdiscal space on L1/2, L2/3 and L3/4 to the kidney ranged from $13.2 \mathrm{~mm}$ to $32.9 \mathrm{~mm}, 20.0 \mathrm{~mm}$ to $27.7 \mathrm{~mm}$, and $20.5 \mathrm{~mm}$ to $46.6 \mathrm{~mm}$, respectively. The distance from the kidney to the interdiscal space at $\mathrm{L} 4 / 5$ was too great to be considered applicable to this study.

\section{Conclusions}

The results of this study might help surgeons better recognize the proximity of the kidney and avoid injury to it during the extreme lateral transpsoas approach to the lumbar spine.

Categories: Urology, Neurosurgery, Orthopedics

Keywords: anatomy, spine surgery, vertebral column, surgery, complications 


\section{Introduction}

The minimally invasive retroperitoneal approach to the lumbar spine was first described by Mayer in 1997 [1,2] followed by McAfee, et al. in 1998 [2] and Pimenta (Pimenta L: Lateral endoscopic transpsoas retroperitoneal approach for lumbar spine surgery. Paper presented at: VIII Brazilian Spine Society Meeting. 2001) and Ozgur, et al. [3] in 2006, who first reported the extreme lateral lumbar interbody fusion procedure. This approach is a minimally invasive technique for lumbar fusion and approaches the lateral lumbar spine via the space between the 12th rib and highest point of the iliac crest to enter the retroperitoneal space and through the psoas major muscle to reach the lumbar spine. This approach allows direct access to the intervertebral disc space with no disruption of the peritoneal structures or posterior paraspinal musculature [4-8].

According to Kwon and Kim [9], disadvantages of the lateral transpsoas approach to the lumbar spine include the learning curve associated with new surgical procedures and the orientation of regional retroperitoneal anatomy, which is often unfamiliar to spine surgeons. Complications caused by this approach include neurologic deficits, injuries to abdominal organs and the ureters, or blood vessels [10]. Interestingly, anatomical studies aimed at the position of the kidney in relation to this approach have not been performed.

Although the left kidney is slightly superior to its counterpart, the kidneys are generally located lateral to the psoas major muscle with a superior border located around the level of the 12th thoracic lumbar vertebra and an inferior border near the level of the third to fourth lumbar vertebrae in the retroperitoneal space, making them vulnerable to injury during the lateral transpsoas approach. This is especially true if there are anatomical variants or pathology involving the kidneys or if the operator is unfamiliar with the three-dimensional anatomy of the retroperitoneum. Therefore, we aimed to dissect the retroperitoneal space to analyze how the extreme lateral transpsoas approach to the lumbar spine might damage the kidneys.

\section{Materials And Methods}

Eight sides from four fresh Caucasian cadavers (two males and two females with a mean age of $79.5 \pm 6.9$ years at death) were used for this study. The specimens were placed in the full lateral position and taped to the dissection table. A skin incision was made into the space between the 12 th rib and the iliac crest. The underlying musculature and aponeuroses were dissected. The retroperitoneum was exposed. Metal wires were then placed into the intervertebral disc spaces. The placement was confirmed using anteroposterior and lateral fluoroscopy. All wires were placed by fellowship-trained spine surgeons. The wires were positioned at L1/L2, L2/L3, L3/L4 and L4/L5 levels. The closest distance from the wires to the kidney was measured by two different surgeons. The position of the kidney in relation to the lumbar vertebrae was documented. The measurement was carried out twice by two observers for a total of four measurements and then averaged. When the distance was more than $50 \mathrm{~mm}$, it was classified as "not applicable (N/A)" because the risk of kidney injury at such a distance is very low. The protocol of the present study did not require approval by the ethics committees of our institutions and the work was performed in accordance with the requirements of the Declaration of Helsinki (64th WMA General Assembly, Fortaleza, Brazil, October 2013).

\section{Results}

The kidneys were easily identified lateral to the lumbar vertebrae. The closest distance from the wires for the disc space of L1/2, L2/3 and L3/4 to the kidney ranged from $13.2 \mathrm{~mm}$ to $32.9 \mathrm{~mm}$ (mean $21.1 \mathrm{~mm}$ ), from $20.0 \mathrm{~mm}$ to $27.7 \mathrm{~mm}$ (mean $24.5 \mathrm{~mm}$ ), and from $20.5 \mathrm{~mm}$ to $46.6 \mathrm{~mm}$ (mean $34.7 \mathrm{~mm}$ ), respectively (Figures 1,2). The distance from the kidney to the disc space at L4/5 was not applicable because on all eight sides the distance was greater than $50 \mathrm{~mm}$. No 


\section{Cureus}

anatomical variants of the kidneys or renal vasculature were identified. No pathological findings such as renal cysts were identified. No specimen had significant abdominal pathological or surgical history in the abdominal area.

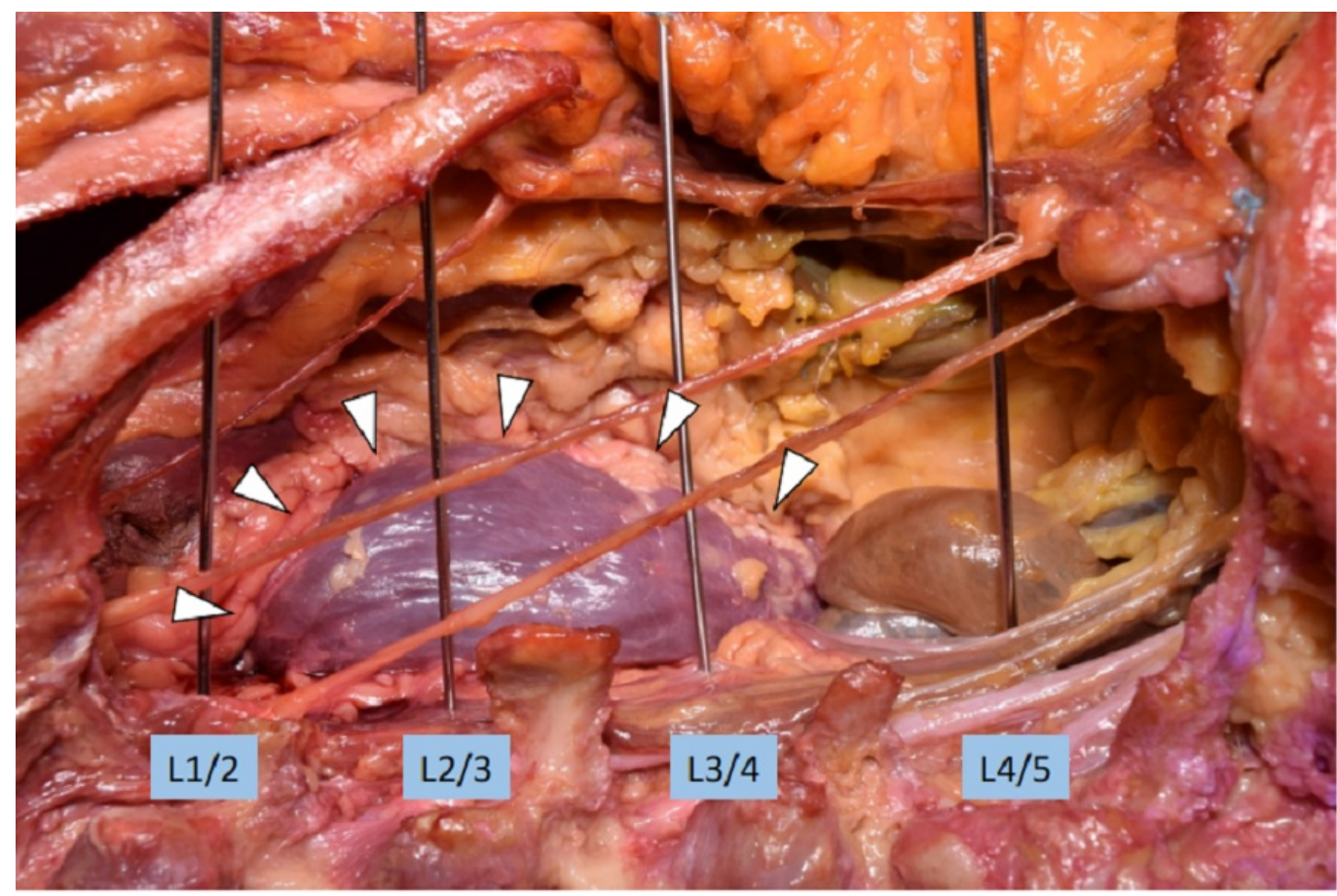

FIGURE 1: Measurement of the closest distance from the wire for the disc space of $L 1 / 2, L 2 / 3$ and $L 3 / 4$ to the kidney (arrowheads).

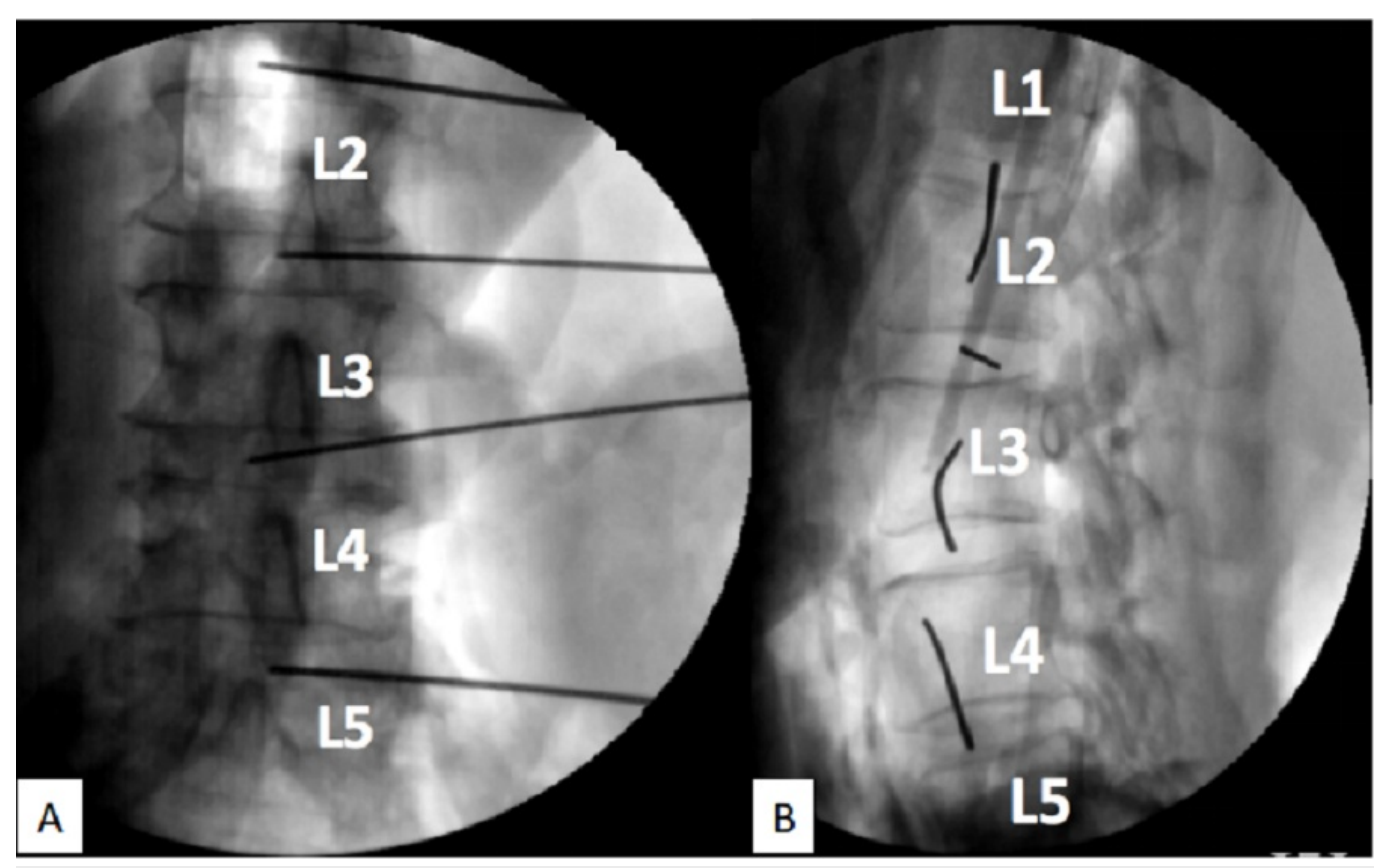

FIGURE 2: Fluoroscopy of the wire trajectory. Note that all the wires are within disc spaces. 


\section{Cureus}

B: Posterior-anterior view

\section{Discussion}

The surgical techniques and clinical outcomes of the extreme lateral transpsoas approach to the lumbar spine have been well documented $[5,6,8,9]$. However, anatomical studies regarding this approach are scant [11-15]. Most of these have focused on neurologic injury [11-15]. Only one report by Voin, et al. [15] has described the anatomical relationships with this procedure and the ureters. To our knowledge, only three cases of iatrogenic renal injury during the extreme lateral transpsoas approach to the lumbar spine have been reported. Blizzard, et al. [16] reported a renal artery injury during the T12-L1 fixation which was successfully identified and treated intraoperatively. Although the details were not included, Isaacs, et al. [17] reported an injury to the kidney with a lateral transpsoas approach. Yuan, et al. [18] reported an injury to the renal vein as a complication of the extreme lateral approach to the lumbar spine. In the present study, the shortest distance to the kidney ranged from 13.2 to $46.6 \mathrm{~mm}$ and for left and right sides, the kidney was nearest the operative field at the L1/2 level.

As the position of the kidneys is variable, preoperative imaging to localize their position might decrease the risks of iatrogenic injury during lateral approaches to the lumbar spine. Normally, the right kidney lies between the first and third lumbar vertebrae and the left kidney is slightly lower than the right. Each kidney is approximately $11 \mathrm{~cm}$ in length, $6 \mathrm{~cm}$ in width and $3 \mathrm{~cm}$ in its anteroposterior dimension. The left kidney is often slightly longer than the right kidney [19].

However, the kidney is one of the most frequent organs to have variations in shape and position. Variants of the kidney such as a horseshoe kidney (Figure 3), a malrotated kidney (Figure 4) or an ectopic kidney often have aberrant renal arteries [20-22]. Such variant renal vasculature might result in a greater risk of kidney injury during a lateral spine approach. According to Satyapal, et al. [23], approximately 28\% of kidneys have accessory renal arteries. Moreover, the course of additional arteries is unpredictable as they can enter the renal hilum either posteriorly or superiorly, or enter directly into the renal parenchyma. Lastly, a retroaortic left renal vein has been detected in approximately 2-4\% of the population [24-29] and brings the renal vein closer to the vertebral column and thus closer into the field of an extreme lateral approach to the lumbar spine. 


\section{Cureus}

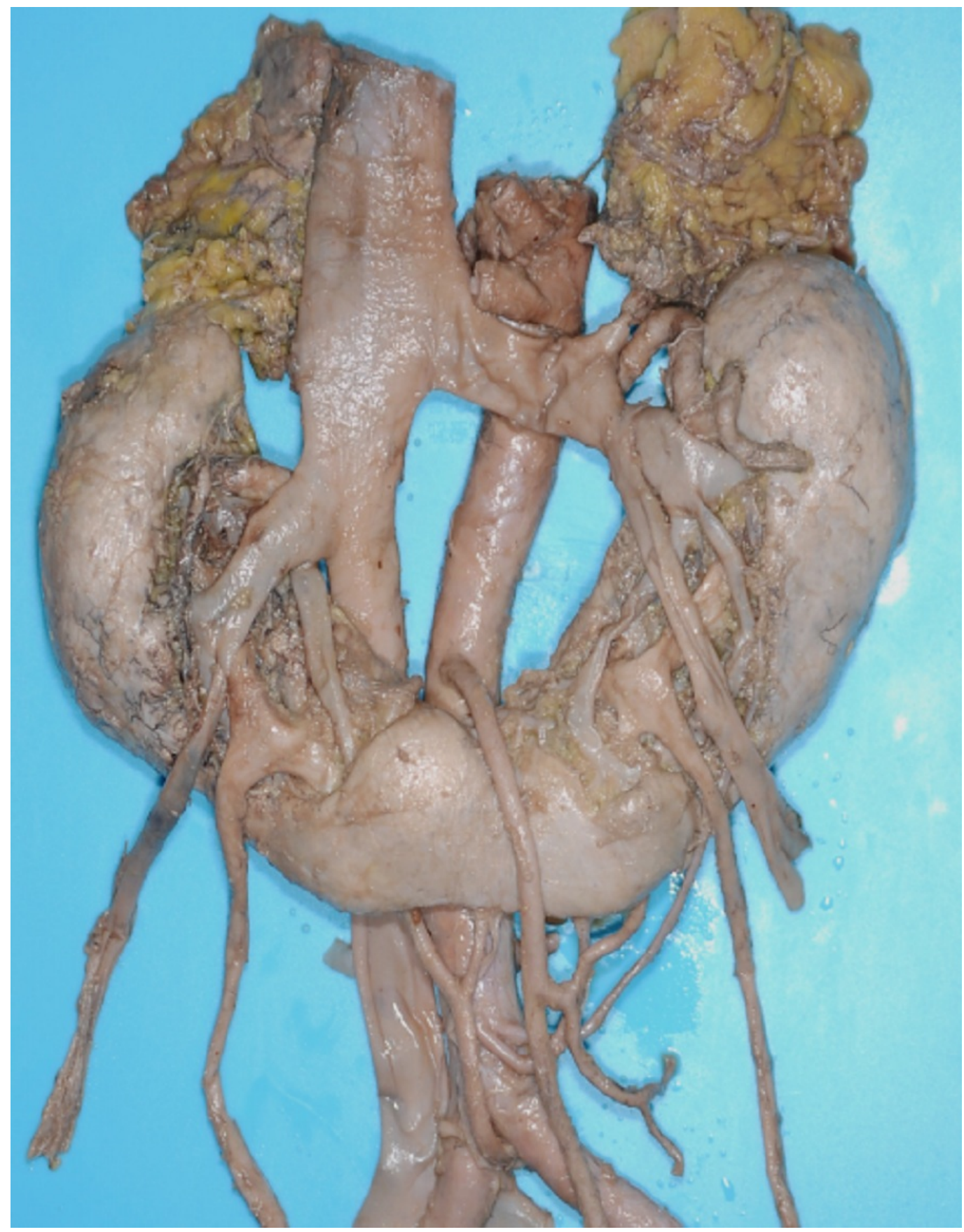

FIGURE 3: Horseshoe kidney.

Slightly lower than normal kidney and often having aberrant renal arteries. 


\section{Cureus}

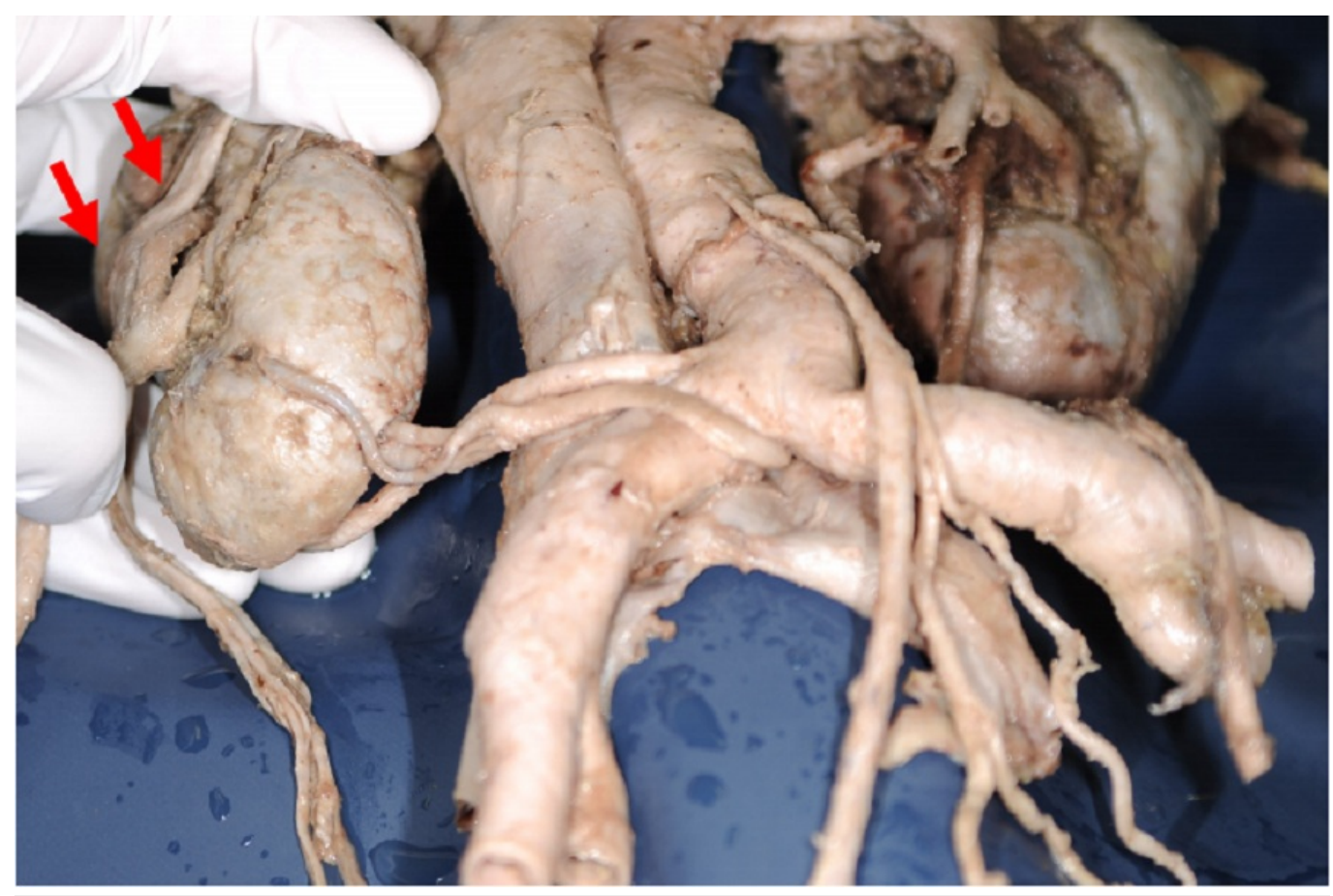

FIGURE 4: Laterally malrotated kidney.

Right renal artery entering the laterally faced hilum (arrows).

\section{Conclusions}

Our anatomical study analyzed possible kidney injury following an extreme lateral transpsoas approach to the lumbar spine. The results of this study might help surgeons better recognize the potential for kidney injury during such a procedure. A better appreciation of the soft tissues adjacent to the spine can improve patient outcomes following spine surgery. As detailed in this paper, due to the variety of pathologies and anomalies that affect the location of the kidneys relative to the spine, pre-operative imaging should be considered in order to avoid injury during the procedure.

\section{Additional Information}

\section{Disclosures}

Human subjects: Consent was obtained by all participants in this study. Animal subjects: All authors have confirmed that this study did not involve animal subjects or tissue. Conflicts of interest: In compliance with the ICMJE uniform disclosure form, all authors declare the following: Payment/services info: All authors have declared that no financial support was received from any organization for the submitted work. Financial relationships: All authors have declared that they have no financial relationships at present or within the previous three years with any organizations that might have an interest in the submitted work. Other relationships: All authors have declared that there are no other relationships or activities that could appear to have influenced the submitted work.

\section{References}

1. Mayer HM: A new microsurgical technique for minimally invasive anterior lumbar interbody fusion. Spine (Phila Pa 1976). 1997, 22:691-669. 10.1097/00007632-199703150-00023

2. McAfee PC, Regan JJ, Geis WP, et al.: Minimally invasive anterior retroperitoneal approach to 
the lumbar spine. Emphasis on the lateral BAK. Spine (Phila Pa 1976). 1998, 23:1476-1484.

3. Ozgur BM, Aryan HE, Pimenta L, et al.: Extreme lateral interbody fusion (XLIF): a novel surgical technique for anterior lumbar interbody fusion. Spine J. 2006, 6:435-443.

10.1016/j.spinee.2005.08.012

4. Rodgers WB, Gerber EJ, Patterson JR: Fusion after minimally disruptive anterior lumbar interbody fusion: analysis of extreme lateral interbody fusion by computed tomography. SAS J. 2010, 4:63-66. 10.1016/j.esas.2010.03.001

5. Caputo AM, Michael KW, Chapman TM Jr, et al.: Clinical outcomes of extreme lateral interbody fusion in the treatment of adult degenerative scoliosis. Sci World J. 2012, 2012:1-5. $10.1100 / 2012 / 680643$

6. Malham GM, Ellis NJ, Parker RM, et al.: Clinical outcome and fusion rates after the first 30 extreme lateral interbody fusions. Sci World J. 2012, 2012:246989. 10.1100/2012/246989

7. Patel VC, Park DK, Herkowitz HN: Lateral transpsoas fusion: indications and outcomes. Sci World J. 2012, 2012:1-6. 10.1100/2012/893608

8. Formica M, Zanirato A, Cavagnaro L, et al.: Extreme lateral interbody fusion in spinal revision surgery: clinical results and complications. Eur Spine J. 2017, 26:464-470. 10.1007/s00586017-5115-6

9. Kwon B, Kim DH: Lateral lumbar interbody fusion: indications, outcomes, and complications . J Am Acad Orthop Surg. 2016, 24:96-105. 10.5435/JAAOS-D-14-00208

10. Uribe JS, Deukmedjian AR: Visceral, vascular, and wound complications following over 13,000 lateral interbody fusions: a survey study and literature review. Eur Spine J. 2015, 24:386-396. 10.1007/s00586-015-3806-4

11. Alkadhim M, Zoccali C, Abbasifard S, et al.: The surgical vascular anatomy of the minimally invasive lateral lumbar interbody approach: a cadaveric and radiographic analysis. Eur Spine J. 2015, 24:906-911. 10.1007/s00586-015-4267-5

12. Benglis DM, Vanni S, Levi AD: An anatomical study of the lumbosacral plexus as related to the minimally invasive ranspsoas approach to the lumbar spine. J Neurosurg Spine. 2009, 10:139144. 10.3171/2008.10.SPI08479

13. Hartl R, Joeris A, McGuire RA: Comparison of the safety outcomes between two surgical approaches for anterior lumbar fusion surgery: anterior lumbar interbody fusion (ALIF) and extreme lateral interbody fusion (ELIF). Eur Spine J. 2016, 25:1484-1521. 10.1007/s00586-0164407-6

14. Karsy M, Jensen MR, Cole K, et al.: Thoracolumbar cortical screw placement with interbody fusion: technique and considerations. Cureus. 2017, 9:e1419. 10.7759/cureus.1419

15. Voin V, Kirkpatrick C, Alonso F, et al.: Lateral transpsoas approach to the lumbar spine and relationship of the ureter: anatomic study with application to minimizing complications. World Neurosurg. 2017, 104:674-678. 10.1016/j.wneu.2017.05.062

16. Blizzard DJ, Gallizzi MA, Isaacs RE, et al.: Renal artery injury during lateral transpsoas interbody fusion: case report. J Neurosurg Spine. 2016, 25:464-466. 10.3171/2016.2.SPINE15785

17. Isaacs RE, Hyde J, Goodrich JA, et al.: A prospective, nonrandomized, multicenter evaluation of extreme lateral interbody fusion for the treatment of adult degenerative scoliosis: perioperative outcomes and complications. Spine (Phila Pa 1976). 2010, 35:322-330. 10.1097/BRS.0b013e3182022e04

18. Yuan PS, Rowshan K, Verma RB, et al.: Minimally invasive lateral lumbar interbody fusion with direct psoas visualization. J Orthop Surg Res. 2014, 9:20. 10.1186/1749-799X-9-20

19. Standring S: Gray's Anatomy: The Anatomical Basis of Clinical Practice. Elsevier Health Sciences, 2015.

20. Iwanaga J, Saga T, Tabira Y, et al.: Contrast imaging study of the horseshoe kidney for transplantation. Surg Radiol Anat. 2015, 37:1267-1271. 10.1007/s00276-015-1501-0

21. Boyan N, Kubat H, Uzum A: Crossed renal ectopia with fusion: report of two patients . Clin Anat. 2007, 20:699-702. 10.1002/ca.20464

22. Iwanaga J, Watanabe K, Saga T, et al.: Bilateral malrotated kidney with major venous variant: a cadaver case report. Int J Anat Var. 2016, 9:43-45.

23. Satyapal KS, Haffejee AA, Singh B, et al.: Additional renal arteries: incidence and morphometry. Surg Radiol Anat. 2001, 23:33-38. 10.1007/s00276-001-0033-y

24. Davis Jr CJ, Lundberg GD: Retroaortic left renal vein: a relatively frequent anomaly . Am J Clin Pathol. 1968, 50:700-703. 10.1093/ajcp/50.6.700 


\section{Cureus}

25. Karaman B, Koplay M, Özturk E, et al.: Retroaortic left renal vein: multidetector computed tomography angiography findings and its clinical importance. Acta Radiol. 2007, 48:355-360. 10.1080/02841850701244755

26. Arslan H, Etlik Ö, Ceylan K, et al.: Incidence of retro-aortic left renal vein and its relationship with varicocele. Euro Radiol. 2005, 15:1717-1720. 10.1007/s00330-004-2563-2

27. Tardieu GG, Edwards B, Alonso F, et al.: Aortic arch origin of the left vertebral artery: an anatomical and radiological study with significance for avoiding complications with anterior approaches to the cervical spine. Clin Anat. 2017, 30:811-816. 10.1002/ca.22923

28. Sanchis-Gimeno JA, Perez-Bermejo M, Rios L, et al.: Analysis of the relationship between the double transverse foramen and the possibility of developing clinical symptoms after whiplash. Clin Anat. 2017, 30:761-766. 10.1002/ca.22897

29. Nourbakhsh A, Yang J, Mcmahan H, et al.: Transverse process anatomy as a guide to vertebral artery exposure during anterior cervical spine approach: a cadaveric study. Clin Anat. 2017, 30:492-497. 10.1002/ca.22858 